\title{
A Faculdade de Direito e a sua importância na História de São Paulo e do Brasil.
}

\author{
Aureliano Leite \\ Presidente do Instituto Histórico e Geográfico \\ de São Paulo.
}

Embora se deva a São Paulo o descobrimento de mais de um têrço do imenso território do Brasil, alcançando a Capitania dominar além da área que lhe sobrou, após a independência, da ocupada hoje pelos estados de Minas Gerais, Santa Catarina (o Paraná pertenceu-lhe até 1853), Rio Grande do Sul, Goiás e Mato Grosso, pouca ou nenhuma importância tiveram os piratininganos nos fatos de nossa História nos últimos tempos da Colônia. Frizo, nos últimos tempos da Colônia. Conseqüência, sem dúvida, de seu empobrecimento, tendo chegado a perder a sua autonomia, que só seria restaurada em 1765 , com a designação do próvido Morgado de Mateus para seu nôvo governador.

Com a vinda da família real de Portugal para o país e a promoção do Brasil a Reino Unido, em 16 de dezembro de 1815, só então os Paulistas começaram a revelar-se na política.

Principiam a aparecer Antonio Carlos e Martim Francisco (José Bonifácio ainda permanecia em Portugal), Diogo Antônio Feijó, o Marechal Almeida e Souza, o Marechal Toledo Rendon, o Desembargador Veloso de Oliveira, o Brigadeiro Gavião Peixoto, Fernandes Pinheiro, Paula Souza, Manuel da Silva Bueno, da família de Amador Bueno, o que não quis ser Rei e outros poucos. 
José Bonifácio, chegado às vésperas do glorioso episódio da Independência, na liderança dessa falange de Paulistas, firma o prestígio da já Província junto do singular Príncipe Regente e de sua inolvidável consorte, a Princesa austríaca Dona Leopoldina.

Até então, São Paulo não dispunha de coisa alguma no que tocava à instrução superior laica, ainda que se fale numa Escola de Medicina criada pelo Capitão General Franca e Horta. A mocidade que possuía recursos monetários rumava para a velha Coimbra. A mocidade pobre contentava-se com aprender disciplinas secundárias e um pouco de Teologia e Retórica com os frades do Convento de São Francisco, pois que o célebre Colégio dos Jesuítas já havia cerrado suas portas, por efeito do banimento de seus chorados componentes, desde 1759.

Por sinal que notáveis sacerdotes brasileiros passaram pelo Convento, tais como Frei Sampaio e Frei Monte-Alverne.

$O$ vasto sobrado no qual viveram os inacinos tornou-se ocupado pelos delegados de Portugal na direção da Capitania.

Aproveitando-se da oportunidade de se pretender criar no país, já Império, dois cursos de Direito, um no Norte, outro no Sul, é quando se pensa em fixar um dos dois cursos em São Paulo.

Mas a oposição contra êsse legítimo pensamento do solo em que nasceu a Pátria é tremenda.

Veremos isso daqui a pouco.

Lembra Antônio Constantino, até a morte serventuário da atual Faculdade, que a primeira tentativa para ser instalado o ensino de Direito no Brasil data de 14 de julho de 1823, quando o santista José Feliciano Fernandes Pinheiro, depois Visconde São Leopoldo, entrou em nossa primeira Assembléia Nacional Constituinte com a indicação propondo que no Império se criasse quanto antes uma Universidade, pelo menos, para assento da qual devesse ser 
preferida a cidade de São Paulo, pelas vantagens naturais e razões de conveniência geral.

"Ficou célebre a frase de Fernandes Pinheiro ao asseverar a necessidade da emancipação do estudo jurídico que, apesar de proclamada a Independência, continuava sujeita aos rançosos cânones de Coimbra, à margem do Mondego. E o ilustre santista ponderou, comparando as duas cidades, a brasileira e a portuguêsa: o Tietê vale bem o Mondego do outro hemisfério.

"Dissolvido o parlamento, a 12 de novembro de 1823 , pela violência autoritária de Pedro I, sòmente a 5 de julho de 1826, é encaminhado pela Comissão de Instrução Pública ao plenário da primeira Câmara Legislativa o projeto sôbre o assunto de autoria do Padre Januário da Cunha Barbosa que, após calorosos debates em que se procurou vetar a preferência por São Paulo, foi convertido na Lei de 11 de agôsto de 1827, instituindo os Cursos Jurídicos na PauJicéia e em Olinda."

Antônio Constantino conclui dizendo que se rompiam os liames coimbrãos com a preponderância brasileira, Há um certo exagêro nessas expressões, porque o método, as disciplinas e os professôres, tudo seguiu por algum tempo e de certa maneira o espirito, os hábitos, o ritual de Coimbra.

Mas a guerra, na imprensa e no parlamento, contra a localização de um dos dois cursos em São Paulo, capital, calcava-se em argumentos como êstes:

a) o clima da Capital era péssimo;

b) falava-se aqui uma linguagem feia;

c) o acesso era difícil, dada a nossa situação geográfica.

Quanto ao clima, realmente para os brasileiros do Norte - São Paulo não agradava - e era José da Silva Lisboa, baiano, depois Visconde de Cairu, e o notável mineiro Bernardo de Vasconcelos, os que mais insistiram nesse e no segundo argumento. 
É lembrar que, bem mais tarde, o condoreiro Castro Alves, que aqui estudou, escrevia para um conterrâneo, na Bahia (Augusto Alvares Guimarães) :

"Se leres poesias nebulosas, germânicas, tiritantes, híbridas, acéfalas, anômalas... não critiques nunca, antes de veres se são de São Paulo, e se forem. cala-te... São Paulo não é Brasil... é um trapo do pólo pregado à goma arábica na fralda da América. ."

Isto, quanto ao clima. Quanto à linguagem, concedamo-lhes também um tanto de razão. A cidade, influenciada pelos ituanos, sorocabanos, tietenses, capivarianos, bragantinos, costumava deturpar a pronúncia do idioma pátrio. Freqüentemente, mesmo entre pessoas educadas, trocava-se o $r$ pelo $l$, e vice-versa.

Isso, além de outros vícios prosódicos que chegaram até os nosso dias. Jamais esquecemos daquele incidente pitoresco, na Universidade de Lisboa, com o nosso saudoso Prof. Waldemar Ferreira. Este, convidado para proferir um curso de Direito Comercial, perante aquela douta casa de ensino superior, o fêz com grande mestria e maior sucesso. Mas, na sua primeira aula, chegou o provocar risadas prolongadas a sua pronúncia bragantina.

O terceiro argumento da distância, pelo menos, para os mineiros não valeu. Pois, tentaram êles levar para a cidade de Mariana uma universidade, quando se discutiu o assunto na Assembléia Constituinte. Ora, a cidade de Mariana localiza-se muito mais distante da orla marítima que a nossa Capital, bem no interior de Minas.

Por sinal que coube ao senado da Câmara de Campanha da Princesa, inspirado talvez no gesto de Bernardo de Vasconcelos, levar à Constituinte a pretensão das Alterosas. Possuimos em nosso arquivo de família a mensagem a respeito, assinada, entre outros, pelo Coronel Matias Moinhos de Vilhena, nosso antepassado materno.

Afinal, S. Paulo ganhou a partida. A profecia do Padre José de Anchieta de que São Paulo seria a Metrópole do Brasil estava a caminho, quando se considerar que, ao lado 
de outros fatôres, a localização dessa casa do Direito à margem do glorioso Rio Tiête contribuiria imensamente para a realização que os dias de hoje testemunham.

Mas em boa hora instalou-se a escola numa parte do colonial casarão do Convento de São Francisco, construído em meados do século XVII, desalojando-se dali os seus frades.

Nesse nobre e vetusto casarão, ocupados os seus dois pavimentos, conservado no centro o pátio claustral, rodeado de arcos romanos, viveu gloriosamente a já chamada Academia até 1936, quando a mudaram para o aparatoso edifício atual, ideado e construído pelo arquiteto luso Ricardo Severo.

Fomos, ao tempo, contra a demolição do vetusto convento. Na verdade, com o progresso espetacular da cidade, o prestigioso e velho estabelecimento de ensino precisava de melhor acomodação. O número de salas de aula tornara-se insuficiente. Faltavam a essas salas e demais dependências condições de higiene, ofereciam-se escuras e sem arejamento bastante.

Verificados êsses graves inconvenientes, sem falar no pior dêles, que era a situação imprópria para uma escola de sua importância no centro tumultuoso da urbe, o que o bom senso aconselhava, parece-nos, era a retirada do estabelecimento para outro local, a Cidade Universitária, por exemplo, e deixar ali, de pé, o tradicional casarão, documento vivo de nosso passado e que podia comportar um de nossos mais expressivos museus históricos.

Lastimàvelmente, o convento, com as suas paredes de autêntica taipa de pilão, contendo sobejos de nossos pró-homens, talvez os do próprio Amador Bueno, reduzidos a pó, sofreram o mesmo destino de outras relíquias paulistanas que a picareta desumana do progresso destruiu - a Igreja do Colégio dos Jesuitas, a Sé Catedral, a Igreja dos Remédios, a Igreja do Rosário, a Igreja do Carmo etc. etc. .

Quando pela primeira vez representámos o Estado de São Paulo na Câmara Federal, ouvimos, dolorosamente, 
partidos de parlamentares de outros estados, os mais veementes ataques contra a demolição do velho prédio da Faculdade. É que êsse prédio era por êles considerado não uma relíquia apenas de nossa capital, mas de todo o Brasil, uma vez que haviam transitado por êle filhos inúmeros de outras regiões nacionais.

Ouvimos calados as justas queixas. Mas, em dado momento, quando as justas queixas dirigiram-se ao então governador Armando de Sales Oliveira, levantámo-nos para defendê-lo, pois o ato não partira dêle, que contrário lhe foi, mas da própria Congregação da Faculdade, então soberana, presidida pelo prestigioso diretor Professor Alcântara Machado.

Todavia, o que foi, foi. Lembram os americanos que não adianta chorar o leite derramado. .

Voltemos, com mais algumas minúcias, aos primeiros tempos da velha Academia, agora chamada Faculdade.

Sendo Ministro do Império o já referido Fernandes Pinheiro, depois Visconde de São Leopoldo, a Academia acabou instalada a $10^{\circ}$ de março de 1828 . Seu primeiro diretor foi o doutor em Direito, por Coimbra, Tenente General José de Arouche Rendon, ao mesmo tempo militar e agricultor, tendo sido o introdutor da cultura do chá na Província. E em que condições? Roubando do Jardim das Alagôas da Corte as mudas que plantou no antigo Largo do Arouche. A escolha do primeiro professor recaíu na pessoa do luso José Maria de Avelar Brotero, também vindo de Coimbra.

Começou sem dúvida nesse momento histórico a participação da Academia nos acontecimentos nacionais.

O já citado Antônıo Constantino, que aliás não se bacharelara em Direito, mas que adorava aquelas famosas Arcadas, narra como se passou a primeira comemoração acadêmica da data de nossa emancipação política:

"Nos seus primórdios, em 1829, a Faculdade, agitada pela crise política do Império, promoveu a comemoração da efeméride da Independência, acontecimento de largas 
repercussões na Paulicéia. Cêrca de 600 acadêmicos (achamos êsse número demasiado, deve tratar-se de apenas 60 acadêmicos), procedentes de todos os pontos do pais, se reuniram na colina do Ipiranga, no sítio onde o Príncipe quebrara os grilhões da Colônia. A exaltação subia ao auge. Ressaltam as crônicas que 600 bôcas beijaram a terra da Independência. Era èsse o ardor acadêmico. Seria dessa forma pelo adentrar dos tempos".

Êsse ano de 1829 marcou o início do ciclo da movimentação patriótica dos moços do curso superior que aqui estudavam e aprendiam a amar a Pátria, procedentes de tôdas os rincões do território emancipado, notadamente de Minas Gerais, de Santa Catarina, do Rio Grande do Sul, do Rio de Janeiro, do Espírito Santo, de Goiás, de Mato Grosso, da própria Bahia. Da Bahia para cima, estudava-se geralmente em Pernambuco.

A Faculdade de Direito tornar-se-ia, destarte, no principal centro de vida cultural, social e cívico, não só de nossa província, como das que acabamos de enumerar.

"São lançados os primeiros jornais, todos sob a influência do Curso Juridico: O Paulista, dirigido por Antonio Mariano de Azevedo Marques, o primeiro poeta da Academia; O Farol Paulistano, dirigido por J. da Costa Carvalho, mais tarde Marquês de Monte Alegre, terceiro diretor da Faculdade; e o Observador Constitucional, do italiano Libero Badaró", que não tardaria a ser bàrbaramente assassinado por sicários pagos por inimigos políticos.

O escritor e jornalista Augusto Emílio Zaluar, que conheceu a cidade em 1860 , deixou em seu conhecido livro Peregrinação pela Província de São Paulo, entre muita coisa mais, estas palavras sôbre o que viu e guardou em seu saco de viagem:

"Apesar da majestosa natureza que circunda a cidade, da suave elevação em que se acha colocada e do ameno clima que a bafeja, São Paulo é triste, monótona e quase desanimada". 
"Quando os estudantes da Faculdade vão às férias, então é que se reconhece melhor o que acabamos de dizer. A mocidade acadêmica imprime à povoação, durante a sua residência nela uma espécie de vida fictícia, que, apenas interrrompida, a faz recaída no seu estado de habitual sonolência."

"A antiga cidade dos Jesuitas deve ser considerada, pois, debaixo de dois pontos de vista. A Capital da Província e a Faculdade de Direito, o burguês e o estudante, a sombra e a luz, o estacionarismo e a ação, a desconfiança de uns e a expansão muitas vêzes libertina de outros, e, para concluir, uma certa monotonia de rotina personificada na população permanente e as audaciosas tentativas do progresso encarnadas na população transitória e flutuante".

Um outro célebre viajante, Eugênio Maria de Hostos, notável publicista puertorriquenho que por aqui transitou alguns anos depois (1874), atribuíu a São Paulo maior adiantamento intelectual sôbre as cidades do interior e outros pontos do Brasil, afirmando que tal se devia à Faculdade de Direito.

Se dessa data saltarmos para os fins do século, encontraremos a célebre artista francesa de origem israelita Sara Bernhart, dando à cidade, pela cultura de seus estudantes, o nome de Capital Artística do Brasil.

Podíamos encarrilhar outras opiniões tôdas concordes na influência de São Paulo, sob o prestígio de sua maior escola, nas letras poéticas e na prosa, assim como o reflexo das Arcadas na própria política nacional.

Nâo seria por menos.

Com paciente cuidado pode-se encontrar, nos trabalhos dos memorialistas José Luiz de Almeida Nogueira e Spencer VAMPRÉ, relação, ano a ano, dos figurões de nomes nacionais que passaram pelo velho Convento, povoando a nossa História Política, Social e Cultural.

Os maiores poetas do país aqui estudaram e alçaram o vôo para a conquista de planos mais altos. De nossa garoa e do convívio com a nossa sociedade patriarcal, do 
casario típico da antiga vila jesuítica, da paisagem do planalto circundado pela Serra da Cantareira e atravessado pelo glorioso Tietê, tiraram a melhor inspiração para os seus versos.

Assim foram Álvares de Azevedo, Fagundes Varela, Castro Alves, Francisco Otaviano, Paulo Eiró, Raimundo Corrêa, Lúcio de Mendonça, Olavo Bilac, Luiz Guimarães, Luiz Murat, Teófilo Dias, Vicente de Carvalho, Afonso Celso, Silvio de Almeida, Pedro Luiz, Batista Cepelos, Alfonso de Guimarães, Guilherme de Almeida e outros menores.

Pelas Arcadas passaram os nossos maiores juristas Teixeira de Freitas, Barão de Ramalho, João Crispiniano Soares, $\Lambda$. Joaquim Ribas, Perdigão Malheiro, Duarte de Azevedo, Ruy Barbosa, Lafayete Pereira, Tavares Bastos, João Mendes Junior e João Mendes, seu pai, Pedro Lessa, Reinaldo Porchat, Carvalho de Mendonça, João Monteiro, Andrade Figueira, Cândido Mota, Spencer Vampré, Almeida Nogueira, Francisco Morato, Dino Bueno, Gama Cerqueira, Alcântara Machado, João Arruda, Brasílio Machado, Estevão de Almeida, Gabriel de Rezende, Veiga Filho, Waldemar Ferreira, Mendes Pimentel, Falcão Filho, Phínio Barreto, Herculano de Freitas, Jorge Americano, Augusto Cesar, Laudo de Camargo, Costa Manso. .

Pelas Arcadas passaram os nossos mais conhecidos estadistas: José Antonio Saraiva, Américo Brasiliense, Gaspar Silveira Martins, Teofilo Otoni, Campos Sales, Rodrigues Alves, Prudente de Morais, Couto de Magalhães, Alberto Torres, Wenceslau Brás, Delfim Moreira, Artur Bernardes, Antonio Prado, Visconde de Ouro Prêto, Florêncio de Abreu, Borges Medeiros, Julio de Castilhos, João Luiz Alves, João Pinheiro, Bias Fontes, Cesário Alvim, Afonso Pena, Bernardino de Campos, Altino Arantes, Antônio Carlos (III), Raul Fernandes, Cerqueira Cesar, Washington Luiz, Julio Prestes, Carlos de Campos, José Carlos de Macedo Soares...

Pelas Arcadas passaram os nossos mais conhecidos diplomatas: Marquês de São Vicente, Barão do Rio Branco, 
Rui Barbosa, Joaquim Nabuco, Ciro de Azevedo, Davi Campista, Salvador de Mendonça, Assis Brasil, Pedro de Toledo, Rodrigues Alves (Filho), José Bonifácio (III).

$\mathrm{E}$ também passaram pelas Arcadas os nossos mais conhecidos jornalistas: Ferreira Viana, F. Rangel Pestana, Almeida Nogueira, Martim Francisco (III), Eduardo Prado, Silva Jardim, Wenceslau de Queiroz, Alberto Sales, José Maria Lisboa Júnior, Plínio Barreto, Júlio Mesquita...

$\mathrm{E}$ ainda os mais renomados romancistas: JoSÉ DE Alencar, Monteiro Lobato, Lucio de Mendonça, Bernardo Guimarães, Godofredo Rangel, Augusto de Lima, Ribeiro Couto, etc. etc.

Nas suas visitas a São Paulo (quatro ao todo), o Imperador D.Pedro II, orgulhoso da obra criada por seu pai, D. Pedro I, costumava visitar a Academia. Não se limitava à simples presença, ao protocolo costumeiro, fazia questão de sentado no estrado, ao lado do lente catedrático, a quem incumbia a preleção, argüir os estudantes.

É de imaginar-se o pavor dos pobres rapazes diante da figura daquele príncipe barbado, de olhos doces, que Victor Hugo chamou de neto de Marco Aurélio.

A única coisa que quebrava um tanto a majestade fisica do Imperador, um belo homem, era a sua voz de falsete.

Por sinal que a alta consideração que os moços acadêmicos sentiam por Pedro II decaíu bastante desde quando um grupo respeitável de políticos, à frente o mineiro Cristiano Ottoni e o pernambucano Saldanha Marinho, alçou na Côrte Imperial a bandeira republicana, lançando o histórico manifesto de 1870.

A idéia do nôvo regime, que aliás, já não constituíu novidade dentro das Arcadas, inflamou a rapaziada. Daí por diante, a República e a Abolição da escravatura passaram a ser a sua preocupação máxima. A pregação se fêz por todos os meios possiveis naquele tempo. Indiscutivelmente, a cooperação daqueles moços nas duas causas deu-lhes muita fôrça. 
Sobretudo a escravatura da pobre criatura negra, arrastada desumanamente do continente africano para o Brasil, inspirou aos seus bardos poemas épicos que enchem páginas de nossa literatura.

A Lei Aurea de 1888, assinada pela magnânima Princesa Isabel, teve com certeza nesses cantos patrióticos e humanos um de seus motivos.

Vem a talho lembrar que ainda existem no mundo, segundo dados fornecidos por uma filantrópica associação inglêsa, alguns milhões de escravos, espalhados na Ásia e em África!

Isso e as guerras mostram que a crueldade da humanidade não desapareceu da face da terra.

Mas, estamos vendo que a importância da Faculdade, desde os seus primeiros dias até os primórdios da República, ou melhor, até, pelo menos, os primeiros lustros do século, era verdadeira e por todos apregoada.

Mas os estudantes nesses gloriosos tempos correspondiam ao valor de seus mestres. Não houve movimento cívico no comêço do século em que não colaborassem salientemente. Assim foi na campanha pelo serviço militar obrigatório, dirigida pelo admirado poeta Olavo Bilac. Assim foi na campanha civilista contra o Marechal Hermes. Assim foi na campanha desenvolvida pela Liga Nacionalista, mandada trancar pelo Presidente Artur Bernardes.

Daí saltando para 1932, chegamos à Revolução Constitucionalista. Nela o papel, quer do corpo discente, quer do corpo docente, marcou páginas cintilantes. O velho convento recolheu e dai partiram os primeiros voluntários civis, compostos em geral de professôres e alunos. Entre os professôres que lutaram de arma na mão, via-se um Ernesto Leme, um Jorge Americano, um Manoel Pinto Pereira. Este, como se considerasse de origem africana, nas horas em que não havia combate, trocava o fuzil por um avental e um gorro espalhafatoso. E exclamava: "Negro nasceu 
para a cozinha"! Era a Academia numa confusão, ou melhor, numa comunhão dos mestres e alunos, naquele casarão que guardava as tradições de nossa raça.

Essa importância, êsse prestígio, abrangia não só estudantes, mas também os mestres.

O caso que vamos lembrar transmite uma idéia de quanto valiam os mestres. O Prof. Pedro Lessa, que lecionou no primeiro ano Filosofia de Direito (1906), era de exigência pouco comum, constituindo verdadeira barreira à conquista da série superior. Quem não soubesse a matéria ensinada não lograva aprovação. Vivia em desacôrdo com os dirigentes da educação, que com medidas irregulares, inadequadas, tumultuavam, anarquizavam o ensino. O Ministro J. J. Seabra, no fim do govêrno Rodrigues Alves, tornou-se um dos responsáveis por tal descalabro. Pedro Lessa reagiu, imaginando e praticando um grande escândalo para chamar a atenção pública sôbre a desmoralização reinante. Aprovou com distinção, grau 10, todos os seus alunos, dissessem as maiores barbaridades nos exames.

Pois bem, êsse professor, ao invés de sofrer um inquérito administrativo, severa punição, foi daí a pouco guindado ao pôsto de Ministro do Supremo Tribunal Federal.

Admirável prestígio dêsse grande mestre!

Quando escrevemos e reunimos em volume Retratos a $P$ ena, nos quais tratámos de várias figuras de seus professôres, oferecêmo-lo ao velho Convento com estas palavras:

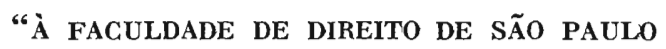

o maior laboratório de homens que tem tido e há-de ter o Brasil".

Experimentamos o grande contentamento, verdadeiro prêmio a nosso esfôrço, de saber a despretenciosa obra apreciada nestes têrmos pelo escritor e pensador JoÃo RIBEIRo, que apenas conheciamos por haver estudado o idioma pátrio na sua primeira Gramática Portuguêsa: 
“"Os "Retratos a Pena" merecem um logar em tôda a biblioteca de brasileiro amigo de sua pátria.

\section{JoÃo RiBEIRO}

\section{Jornal do Brasil — 22-5-929""}

Atrás, reproduzimos conceitos de viajantes estrangeiros sôbre a Faculdade. Mas quem melhor e mais coloridamente parece exprimir a admiração pela nossa escola foi o notável escritor e jornalista Lucio DE MENDONÇA, já por nós citado, que freqüentou os seus duros bancos até 1870 .

Dêmos-lhe a palavra:

"Ali, sob aquêle amplo céu, onde parece que ainda vagam na imortalidade da glória os grandes espíritos de seus melhores filhos, Rodrigues dos Santos, Paula Souza, Feijó, e outros, cujos nomes constelam as tradições paulistanas; ali, na vasta esplanada, varrida de ventos, alta, tão alta que de lá se avista o futuro do Brasil inteiro; ali, na luta obscura e porfiada, ainda que ao lado de atletas e recebendo nas armas leais o reflexo de seus triunfos, nutri-me do pão dos fortes, enrijei-me às auras vitais daquela terra; bebi, a longos sorvos, o seu alento vigoroso; aqueci o peito ao calor de seu peito de gigante; - verme, senti arrojos de águia; encarei de face com o Sol; antevi, em sonhos grandiosos, o largo destino da pátria republicana, e, no solo paulista, tive o orgulho de ser brasileiro".

E assim conclui Lúcio DE MendonçA:

"Terra sagrada de homens honrados, terra a que eu devo, mais do que o nascimento, a educação cívica; berço de minha crença, formosa terra de São Paulo, nobre plebéia robusta, mãe de espíritos, leôa que amamenta as almas modernas, que vão da luta a grande luta, salve! em nome da mocidade e do povo, salve! mãe intelectual de nossa nacionalidade, esperança de nossa redenção, alma do Brasil nôvo, coração de pátria livre!" 
Nesse magnífico hino a São Paulo sente-se no fundo, o seu amor religioso pela escola que lhe deu a sua carta de bacharel.

É não esquecer também outro aluno da Faculdade, o chamado Águia de Haia, Rư Barbosa, citado por CÂndido MotTa Fil.Ho, nestes parágrafos lapidares:

"O regime imperial quase logo após a nossa independência consagrou ao Direito duas faculdades, uma ao Norte, outra ao Sul, como situações polares, dominantes ao nosso mundo moral. Sem desfazer, porém, na realeza de Olinda, a pérola do Norte, amortecida, talvez, mas não desluzida, jamais, do seu Oriente, não se poderia sèriamente duvidar que o magistério de São Paulo exerceu sempre um grau mais alto, com influência muito mais poderosa e muito mais larga amplitude a sua missão nacional".

E acresceu Rui Barbosa:

"Bolonha, famosa outrora entre as cidades letradas pela sua universitá scholariam e pelos seus doctores legentes, se chamava por antonomásia, a um tempo, a douta $e$ a livre, associando nas suas antigas moedas a legenda solene de seu direito: libertas, o fôro por excelência do mestre: Bononia docet. A São Paulo, indisputàvelmente, lhe cabem os dois títulos no mesmo brasão: - professa a liberdade e ensina a Justiça".

Comentando êsse trecho de Rur, diz Motta Filho:

"Muito embora não recusando o influxo coimbrão, tendo como professôres mestres preparados em Coimbra, a Faculdade de São Paulo iniciou a emancipação intelectual da Cultura brasileira: A cidade se transfigura. Toma nova fisionomia, adquire novos centros de interêsse, de seus novos problemas, amolda, por fim, uma nova mentalidade."

Para terminar, apesar de que se reconheça que a velha Faculdade, com o desenvolvimento fabuloso da cidade, mesmo no campo da educação e cultura, encontra hoje numerosos concorrentes espalhados por todo o Estado, é-se obrigado a ponderar que a despeito de instalada em apa- 
ratoso prédio moderno, ainda que mal situado, com mais de três mil alunos, goza ainda de alto conceito, considerada que é das mais famosas escolas no gênero da América.

Assim sendo, mantém de certa maneira boa parcela de colaboração efetiva na vida social e cultural da Nação.

0 invejável progresso material a que o Estado atingiu, deveu-se à sua lavoura da rubiácea abissínica, que encontrou no braço livre para que o imigrante europeu grandemente contribuíu, substituindo o infeliz trabalhador escravo, o seu melhor propulsor.

Esse progresso ganhou também impulso no desenvolvimento da indústria, conseqüência inegável da preponderância do café, que acabou sobrepujado pela maquinaria.

Sabemos que estamos repetindo um truísmo. Mas é para lembrar que êsse estupendo progresso material de hoje teve um coadjuvante indiscutível no alto nível da instrução superior de São Paulo, da qual, até alguns lustros do século XIX, a mais forte expressão foi a tradicional Faculdade do Largo de São Francisco, vinda em boa hora, aos 1827, governando o país êsse estouvado príncipe a que o Brasil deve a sua emancipação - Dom Pedro de Bragança. 